\title{
In Vitro Propagation of Traditional Italian Hazelnut Cultivars as a Tool for the Valorization and Conservation of Local Genetic Resources
}

\author{
Loretta Bacchetta ${ }^{1}$, Maria Aramini, and Claudia Bernardini \\ UTS Biotecnologie sez. Genetica Genomica, ENEA Casaccia, Via \\ Anguillarese 301-0060, Rome, Italy \\ Eddo Rugini \\ Dipartimento di Produzione Vegetale sez. Ortofloroarboricoltura, Università \\ degli Studi della Tuscia, Via Camillo De Lellis 1-01100 Viterbo, Italy
}

Additional index words. Corylus avellana, hazelnut, traditional germplasm, in vitro culture

Abstract. The hazelnut (Corylus avellana) is one of the most important crops in the Mediterranean basin. The availability of efficient and reliable in vitro propagation could valorize the local genetic resources. Different studies have been carried out for the definition of an efficient hazelnut micropropagation protocol. These have usually been performed on the most important cultivars, but the application of the micropropagation protocol to the minor ones has produced contradictory results and the technique sometimes had less success than the traditional one. The aim of this work was to gather knowledge and additional information on the in vitro performance of some minor cultivars in comparison with the most used for micropropagation. A revised procedure for the specific medium formulation is suggested. The sterilization and culture establishment phases are discussed in detail. The role of zeatin and 6-benzylamminopurine (BA) in shoot proliferation in the Italian traditional cultivars is compared to improve this phase. The rooting stage proves to be one of the most crucial steps in achieving a large-scale commercial application of hazelnut micropropagation.

Corylus avellana L. (Betulaceae) represents an economically important crop in the European Community, particularly in the biogeographic Mediterranean basin (http:// www.fao.org/). Hazelnuts are produced principally in Turkey, Italy, the United States, and Spain $(550,000,110,000,25,000$, $18,000 \pm$ tons, respectively, per year) followed by France, Greece, and Portugal. Approximately $90 \%$ of production is shelled and sold as kernels, whereas the remaining $10 \%$ goes to fresh consumption. Interest in this species is also the result of its excellent nutritional and nutraceutical properties (Phillips et al., 2005; Sivakumar and Bacchetta, 2006; Sivakumar et al., 2005). Moreover, in the typical cultivation areas, traditions and cultural identity are strongly tied to hazelnut

Received for publication 19 Sept. 2007. Accepted for publication 28 Nov. 2007.

This work was carried out with the financial support of the MIUR (Italian Ministry of Industry and Scientific Research) Project Agrobiotecnologie Scrigno and EU AGRI GEN RES 068 Safenut Project.

We are grateful to Dr. Giovanna Zappa for her useful suggestions and chemical assistance. Our acknowledgments to Dr. Alessandro Zini Alessandro for critical statistical reading and Ian Pace for English written review.

${ }^{1}$ To whom reprint requests should be addressed; e-mail loretta.bacchetta@casaccia.enea.it production, whereas the latter also contributes to a suitable use and recovery of marginal land. Even if, in some regions, this crop is not the major agricultural resource, it nevertheless represents an interesting source of income for the local sustainable production system and a precious food for traditional local use. Italy, the world's second largest producer, boasts several traditional cultivars, which are mainly cultivated in Campania, Latium, Piedmont, and Sicily with a large number of local genotypes (Bacchetta et al., 2005). In the last few years, some of the major cultivars (Tonda Romana from Latium, Tonda di Giffoni from Campania, and Tonda delle Langhe from Piedmont) obtained the European Community quality stamp for their quality and traditional peculiarity. Moreover, these cultivars are often introduced into other countries to increase their range of cultivated genotypes, because they are easily adaptable and productive.

Traditional hazelnut propagation in Italy is mostly carried out by farmers themselves using the suckers of "vigorous mother plants" selected in orchards. Without certified materials, it is possible to spread diseases widely (Scortichini, 2002) or reproduce materials of unknown origin. The use of biotechnologies such as micropropagation promotes the production of healthy and true-to-type materials (Nas et al., 2004), improving the economic value of the crop.
Using micropropagation, the breeding program could be accelerated by a rapid distribution of standard or new cultivars.

One of the main limitations of hazelnut in vitro propagation from mature tissues is the high degree of endogenous contamination (Diaz-Sala et al., 1990; Nas and Read, 2004; Reed et al., 1998), which makes the establishment of the culture a very laborious and timeconsuming phase.

Moreover, several media formulations have been proposed for optimizing shoot multiplication and elongation in the main hazelnut cultivars (Andres et al., 2002; Damiano et al., 2005; Messeguer and Mele, 1987; Yu and Reed, 1993). However, when the standardized protocol was applied to local and minor cultivars, the results were contradictory and some difficulties in shoot growth were observed (Bacchetta et al., 2005). Nas and Read (2004) recently proposed a novel method for medium formulation based on the concept that nut nutritional reserves are able to guarantee suitable conditions for seedlings as well as for in vitro shoots. However, there are physiological differences between seed tissues and the somatic parts of plants. Moreover, the concentration of essential nutritional compounds present in seeds can be too high or toxic for somatic tissues.

In the present work, this approach was slightly revised and the mineral hazelnut medium formulation was optimized by using the differences in seed macro- and microelements of two species, one of them well adapted to in vitro conditions.

Because the success of micropropagation is the result of a combination of many factors, including tissue type and hormone requirement, the effect of the physiological stages of the initial explants on culture establishment and the influence of zeatin or 6-benzylamminopurine (BA) concentrations in stimulating shoot proliferation were evaluated.

These goals met the objectives of research project SCRIGNO, supported by the Ministry of Industry and Scientific Research, aimed at evaluating local agrobiodiversity for "typical, traditional" products and meet those of the AGRI GEN RES 068 Safenut EU program covering the characterization, conservation, and utilization of genetic resources.

\section{Materials and Methods}

Development of the hazelnut-specific medium. Prunus dulcis was chosen as the reference species (Rugini and Verma, 1983) and the ratio of the mineral nut material between the two species was used as the Murashige and Skoog medium (MS) mineral composition correction factor (Murashige and Skoog, 1962). This approach took account of the importance of seed composition as a starting point for formulation of the culture medium but suggested a tool for balancing medium composition as closely as possible with the demands of somatic tissue growth.

Mineral composition (macro- and microelements) was estimated with (inductively 
coupled plasma-atomic emission spectrometry VARIAN S.p.A. (VISTA MPX assail configuration) applied to the fresh leaves and raw seeds of both almond (Prunus dulcis) and hazelnut (Corylus avellana) samples $(100 \mathrm{~g})$ collected in orchards located near Viterbo (Central Italy). The procedure for developing the novel medium was as follows: determination of anions and cations of MS salt medium; evaluation of the ratio between the concentrations of mineral elements found in hazelnut and almond seeds (factor of correction); use of the correction factor for calculating the cation and anion amounts and for estimating the new concentrations of salts; the quantity of $\mathrm{KI}$ was unchanged while the quantity of potassium in $\mathrm{KH}_{2} \mathrm{PO}_{4}$ was calculated after phosphorous (Rugini, 1984). The novel formulation was a modified MS medium, which we term HM induction, supplemented with vitamins $\mathrm{MS}, 200 \mathrm{mg} \cdot \mathrm{L}^{-1}$ myo-inositol as suggested by Nas and Read (2004), gibberellic $\mathrm{A}_{3}\left(\mathrm{GA}_{3}\right) \quad 0.4 \mathrm{mg} \cdot \mathrm{L}^{-1}$, indole-3-butirric acid (IBA) $0.05 \mathrm{mg} \cdot \mathrm{L}^{-1}$, $3 \%$ sucrose, and BA $\left(0.5 \mathrm{mg} \cdot \mathrm{L}^{-1}\right)$.

Explant source. Tissue culture was initiated using uninodal shoot explants $(1 \mathrm{~cm}$ in length) gathered from potted plants. The plants were 2 years old and were obtained from rooted suckers of six Italian cultivars (Tonda Romana, from Latium; Tonda Giffoni, Avellana Speciale, and Mortarella from Campania; Napoletanedda and Ghirara from Sicily) in an ex situ hazelnut plant collection located in Vico Matrino (Viterbo, Central Italy). The suckers were potted in Feb. 2003 and were grown in 30-cm-diameter plastic pots containing clay, sand, and peat in a $1: 1: 1$ ratio. The potted plants, used as "mother plants," were maintained in a healthy state under natural light and were periodically fertilized, pruned, and treated with fungicides.

Sterilization procedure. Primary explants were washed in tap water $(1 \mathrm{~h})$, cleaned with a disinfectant, antibacterial soap (Lysoform Medical, Lever Fabergè, Italy), and then rinsed again with tap water. The sterilization was performed by immersion in $70 \%$ ethanol for $5 \mathrm{~s}$. After the recut of basal ends, the explants were surface-sterilized with $0.05 \%$ $\mathrm{Na}$ Merthiolate $\left(\mathrm{C}_{\mathrm{g}} \mathrm{H}_{\mathrm{g}} \mathrm{H}_{\mathrm{g}} \mathrm{NaO}_{2} \mathrm{~S}\right.$ Carlo Erba) for $10 \mathrm{~min}$, a few drops of Tween-20 (SigmaAldrich, Steinheim, Germany) were added, and then the explants were rinsed in sterile, distilled water three times ( $5 \mathrm{~s}$ each time). Sodium hypochlorite $(1: 5 \mathrm{v} / \mathrm{v})$ for $10 \mathrm{~min}$ and a few drops of Tween-20 were only used for explants collected during winter. Before inoculation onto the culture medium, the basal ends of each explant were renovated to favor the absorption of nutrients.

Establishment of in vitro culture and rooting. The uninodal explants were collected in the two different physiological phases of the plants: rapid growth and the dormant phase (the spring and winter seasons, respectively) and inoculated onto the $\mathrm{HM}$ induction medium. In the second subculture, BA $\left(1.5 \mathrm{mg} \cdot \mathrm{L}^{-1}\right)$ or zeatin $\left(1 \mathrm{mg} \cdot \mathrm{L}^{-1}\right)$ was added after autoclaving to HM to promote proliferation.
Rooting was stimulated with: 1) shoot basal end immersion in an IBA solution (1 $\mathrm{mg} \cdot \mathrm{L}^{-1}$ ) for $20 \mathrm{~s}$ and 20 -d culture on the HM medium without hormones; or 2) 1-month culture on the one-third HM mineral content supplemented with IBA $\left(2 \mathrm{mg} \cdot \mathrm{L}^{-1}\right)$. As suggested by different authors, a reduction of the medium mineral concentration can increase the rooting percentage (Rodriguez et al., 1989).

The media were adjusted to $\mathrm{pH} 5.7$ before adding $0.7 \%(\mathrm{w} / \mathrm{v})$ agar (Plant Agar Duchefa) and autoclaved at $121^{\circ}$ for $20 \mathrm{~min}$. The explants were cultured in a growthconditioned chamber at $25 \pm 1{ }^{\circ} \mathrm{C}$ with a 16-h photoperiod $\left(32 \mu \mathrm{mol} \cdot \mathrm{m}^{-2} \cdot \mathrm{s}^{-1} \mathrm{cool}-\right.$ white fluorescent illumination) and $70 \%$ to $80 \%$ relative humidity. Thirty milliliters of medium were distributed into glass test tubes (12 cm length, $3 \mathrm{~cm}$ diameter) with plastic lids.

Experimental design. One hundred uninodal auxiliary buds of each hazelnut cultivar were cultured in separate glass test tubes containing $30 \mathrm{~mL}$ of medium. Ten replications (test tubes) of each cultivar were randomly applied to each treatment. At the end of the subculture $(30 \mathrm{~d})$, shoot length, auxiliary bud (node) number, and fresh and dry weight of shoots were recorded. The appearance of plantlets was visually evaluated. The experiment was repeated once. Data for the explants in a culture vessel were divided by the number of explants, and the mean shoot length and auxiliary bud numbers were used for statistical analysis. The statistical analysis was completed using SPSS (13.0; SPSS, Chicago): descriptive analysis and general linear model multivariate at $P \leq 0.05$.

\section{Results and Discussion}

Hazelnut revised medium. Table 1 contains the concentrations of macro- and microelements in both hazelnut and almond nuts and leaves. Differences were found for B, $\mathrm{Ba}, \mathrm{Mn}, \mathrm{Cu}, \mathrm{Si}$, and $\mathrm{Sr}$ concentrations, which showed higher values in hazelnuts than in almonds. On the other hand, $\mathrm{Fe}$ and $\mathrm{Zn}$ displayed lower concentrations in hazelnut. Mobdilene was not found in either the kernel or leaves of either. Among macroelements, $\mathrm{Ca}$ and $\mathrm{Mg}$ were consistently lower in Corylus avellana than in Prunus dulci. The novel medium HM, developed on the basis of these differences, is shown in Table 2. With respect to $\mathrm{MS}$, the $\mathrm{HM}$ medium shows reduced concentrations of $\mathrm{CaCl}_{2}, \mathrm{MgSO}_{4}$, and $\mathrm{KH}_{2} \mathrm{PO}_{4}$ and includes $\mathrm{K}_{2} \mathrm{SO}_{4}$, which is missing in both MS and NRM. Among microelements, $\mathrm{B}$ increased in the form of $\mathrm{H}_{3} \mathrm{BO}_{3}$ and $\mathrm{Mn}$ in the form of $\mathrm{MnSO}_{4}$. On other hand, $\mathrm{Zn}$ concentration in $\mathrm{HM}$ was reduced to $1: 4$ compared with MS and NRM media. Sucrose was chosen as the carbon source, even if previous experiments showed the positive effect on hazelnut shoot elongation of both glucose and fructose; shoots with a good general appearance and growth habit were also observed in a medium supplemented with lactose (data not shown). Analogous results were reported by $\mathrm{Yu}$ and Reed (1993) in hazelnut, but an alternative carbon source to sucrose was reported to improve growth and the multiplication rate in this and other tree species by Ding et al. (1985) and Marino et al. (1993).

Inoculation phase. The ongoing limitations of hazel micropropagation are attributed not only to the reduced specific morphogenetic capacity of explants, but also to the contamination found in plant materials (Diaz-Sala et al., 1990; Reed et al., 1998). Damiano et al. (2005) reported that $\approx 95 \%$ of explants could be infected, limiting the advantage of in vitro culture. The availability of "mother plants" cared for in pots facilitated sterilization because of the reduced endocontamination of the initial plant material. Using these plants as initial explants, the percentage of contamination decreased by $\approx 20 \%$ to $30 \%$ compared with the material collected directly in the field.

Buds also seemed particularly sensitive to the sterilizing products and displayed necrosis of tissues. This phenomenon was evident especially in actively growing explants. In this case, Na-merthiolate proved more effective

Table 1. Chemical composition of hazelnut and almond kernels and leaves

\begin{tabular}{|c|c|c|c|c|}
\hline \multirow[b]{2}{*}{ Chemical composition } & \multicolumn{2}{|c|}{ Kernels } & \multicolumn{2}{|c|}{ Leaves } \\
\hline & Hazelnut & Almond & Hazelnut & Almond \\
\hline \multicolumn{5}{|l|}{ Microelements $(\mu \mathrm{g} \cdot \mathrm{g})$} \\
\hline $\mathrm{Al}$ & 3.6 & 2.8 & 182.0 & 197.0 \\
\hline B & 53.7 & 48.7 & 63.4 & 49.5 \\
\hline $\mathrm{Ba}$ & 30.0 & 4.7 & 275.0 & 43.2 \\
\hline $\mathrm{Cu}$ & 13.9 & 15.9 & 21.8 & 17.7 \\
\hline $\mathrm{Fe}$ & 31.3 & 40.0 & 333.0 & 352.0 \\
\hline $\mathrm{Mn}$ & 65.2 & 16.8 & 578.0 & 48.2 \\
\hline $\mathrm{Na}$ & 15.8 & 29.1 & 452.0 & 391.0 \\
\hline $\mathrm{Rb}$ & 64.8 & 20.6 & 269.0 & 151.0 \\
\hline $\mathrm{Si}$ & 6.7 & 3.4 & 133.0 & 130.0 \\
\hline $\mathrm{Sr}$ & 34.5 & 4.5 & 345.0 & 67.6 \\
\hline $\mathrm{Zn}$ & 20.1 & 58.7 & 69.9 & 76.5 \\
\hline \multicolumn{5}{|l|}{ Macroelements $(\mu \mathrm{g} \cdot \mathrm{g})$} \\
\hline $\mathrm{Ca}$ & $1,371.8$ & $2,391.0$ & 11,369 & 16,211 \\
\hline $\mathrm{K}$ & $6,533.7$ & $6,653.2$ & 19,300 & 28,093 \\
\hline $\mathrm{Mg}$ & $1,549.6$ & $2,537.5$ & 3,940 & 4,880 \\
\hline $\mathrm{P}$ & $2,698.4$ & $5,755.7$ & 7,085 & 4,775 \\
\hline $\mathrm{S}$ & $1,490.2$ & $1,403.3$ & 4,171 & 3,148 \\
\hline
\end{tabular}


than Na-hypochlorite, because it is able to penetrate cells without causing necrosis (data not shown). Moreover, according to our results, isolated buds were the most suitable

explants for in vitro establishment of hazelnut dormant cultivars; the percentage of healthy responsive explants was higher in single buds than in uninodal explants (Bacchetta

Table 2. The composition of HM in comparison with MS (Murashige and Skoog, 1962) and NRM (Nas and Read, 2002).

\begin{tabular}{|c|c|c|c|}
\hline & HM & MS & NRM \\
\hline \multicolumn{4}{|c|}{$\overline{\text { Macroelements }\left(\mathrm{mg} \cdot \mathrm{L}^{-1}\right)}$} \\
\hline $\mathrm{NH} 4 \mathrm{NO}_{3}$ & 1,650 & 1650 & 530 \\
\hline $\mathrm{Ca}\left(\mathrm{NO}_{3}\right)_{2} \cdot 4 \mathrm{H}_{2} \mathrm{O}$ & - & - & 700 \\
\hline $\mathrm{CaCl}_{2} \cdot 4 \mathrm{H}_{2} \mathrm{O}$ & 190.46 & 440 & 90 \\
\hline $\mathrm{MgSO}_{4} \cdot 7 \mathrm{H}_{2} \mathrm{O}$ & 225.60 & 370 & 1,600 \\
\hline $\mathrm{KNO}_{3}$ & 1,840 & 1900 & 550 \\
\hline $\mathrm{KH}_{2} \mathrm{PO}_{4}$ & 80.05 & 170 & 1,300 \\
\hline $\mathrm{K}_{2} \mathrm{SO}_{4}$ & 73.00 & - & - \\
\hline \multicolumn{4}{|l|}{ Microelements $\left(\mathrm{mg} \cdot \mathrm{L}^{-1}\right)$} \\
\hline $\mathrm{H}_{3} \mathrm{BO}_{3}$ & 6.8 & 6.2 & 6.2 \\
\hline $\mathrm{CuSO}_{4} \cdot 5 \mathrm{H}_{2} \mathrm{O}$ & 0.022 & 0.025 & 2.5 \\
\hline $\mathrm{MnSO}_{4} \cdot \mathrm{H}_{2} \mathrm{O}$ & 65.59 & 16.9 & 20.0 \\
\hline $\mathrm{Na}_{2} \mathrm{MoO}_{4} \cdot 2 \mathrm{H}_{2} \mathrm{O}$ & - & 0.25 & 2.5 \\
\hline $\mathrm{ZnSO}_{4} \cdot 7 \mathrm{H}_{2} \mathrm{O}$ & 2.57 & 8.6 & 8.8 \\
\hline $\mathrm{Zn}\left(\mathrm{NO}_{3}\right)_{2} \cdot 6 \mathrm{H}_{2} \mathrm{O}$ & - & - & - \\
\hline Sequestrene $138 \mathrm{Fe}$ & & - & 100 \\
\hline $\mathrm{FeSO}_{4} \cdot 7 \mathrm{H}_{2} \mathrm{O}$ & 28.72 & 27.8 & - \\
\hline $\mathrm{Na}_{2} \cdot$ EDTA & 37.30 & 37.3 & - \\
\hline $\mathrm{KI}$ & 0.85 & 0.83 & - \\
\hline $\mathrm{CoCl}_{2} \cdot 6 \mathrm{H}_{2} \mathrm{O}$ & 0.03 & 0.025 & - \\
\hline \multicolumn{4}{|l|}{ Vitamins $\left(\mathrm{mg} \cdot \mathrm{L}^{-1}\right)$} \\
\hline Thiamine (B1) & 0.60 & 0.1 & 0.60 \\
\hline Riboflavin (B2) & 0.21 & - & 0.21 \\
\hline Nicotin acid (B3) & 1.15 & 0.5 & 1.15 \\
\hline Pyridoxine (B6) & 0.60 & 0.5 & 0.60 \\
\hline$\alpha$-Tocopherol (E) & 20.00 & - & 20.00 \\
\hline Vitamin $\mathrm{C}$ & 1 & - & 1.00 \\
\hline Glycine & 0.85 & 2.0 & 0.85 \\
\hline Folic acid & - & - & - \\
\hline Biotin & - & - & - \\
\hline Myo-inositol & 200 & 100 & 200 \\
\hline Sucrose $\left(g \cdot \mathrm{L}^{-1}\right)$ & 30 & 30 & 30 \\
\hline $\operatorname{Agar}\left(g \cdot L^{-1}\right)$ & & 10 & $5-6$ \\
\hline Gelrite $\left(g \cdot \mathrm{L}^{-1}\right)$ & - & - & - \\
\hline
\end{tabular}

Table 3. Effect of cold storage and kind and size of initial explants on in vitro response of hazelnut dormant materials.

\begin{tabular}{llcc}
\hline & \multicolumn{3}{c}{ Shoot-buds (\%) $)^{\mathrm{z}}$ Mean value \pm SD } \\
\cline { 2 - 4 } Type of plant material & T & Outgrowth & Necrosis symptoms \\
\hline Cold treatment & NT & $53 \pm 1.4$ & $21 \pm 1.4$ \\
Size of explants & SB & $30 \pm 0.6$ & $50 \pm 0.7$ \\
& WB & $52 \pm 0.1$ & $25 \pm 1.5$ \\
& $26 \pm 1.4$ & $49 \pm 0.8$ \\
\hline
\end{tabular}

${ }^{\mathrm{z}}$ Mean values \pm SD of six hazelnut cultivars.

$\mathrm{T}$ and $\mathrm{NT}=$ explants storage and non at $5{ }^{\circ} \mathrm{C}$ per 3 weeks; $\mathrm{SB}$ and $\mathrm{WB}=$ single buds or single node segments. et al., 2005). The same considerations were reported by Messeguer and Mele (1987) for the in vitro establishment of the Spanish cv. Negret. The removal of external leaflets, before inoculation, facilitates the development of explants by reducing the necrosis of tissues after the sterilization procedure (by $25 \%$ compared with the whole buds). Damiano et al. (2005) reported that one of the main difficulties for hazelnut in vitro culture was the necrosis of buds after inoculation. On the other hand, treatment with a low temperature improved the in vitro morphogenetic capacity of dormant materials. Storage at $5{ }^{\circ} \mathrm{C}$ for almost 3 weeks of hazel twigs, before the sterilization process, induced $50 \%$ of sterile shoots instead of $30 \%$ for the untreated materials, owing to the effect of cold on endogenous pathogen contamination (Table 3 ).

Culture establishment. The response to the novel medium of six hazelnut cultivars is reported in Table 4. Explants cultured on HM showed green-colored leaves and relatively low calluses at their basal ends. Explants cultured on MS were usually chlorotic and produced almost no callus on their basal end. In general, all the cultivars exhibited a similar ranking of shoot lengths and number of auxiliary buds per shoot on the two media. However, the significant medium $\times$ genotypes interaction showed that, when the medium was favorable, the length and numbers of buds per shoot were enhanced. Moreover, the quality of plantlets was improved because of the positive effect of the medium on the fresh and dry weights of shoots. Shoot proliferation was absent on both media, as also reported by Nas and Read (2004). However, the culture medium affected the potential multiplication rate; longer shoots are also more suitable for subsequent propagation.

The physiological stage of explants affected the shoot length of cvs. Tonda Giffoni and Tonda Romana, which displayed growth differences between explants collected during spring or winter and inoculated on the HM induction medium (Fig. 1). On the other hand, cvs. Mortarella, Ghirara, Avellana Speciale, and Napoletanedda showed a similar shoot lengthening using the two kind of explants. Basically all the cultivars

Table 4. In vitro response of six hazelnut traditional cultivars to the revised medium HM in comparison with Murashige and Skoog (MS).

\begin{tabular}{|c|c|c|c|c|c|c|c|c|}
\hline \multirow[b]{2}{*}{ Cultivars } & \multicolumn{4}{|c|}{ MS medium } & \multicolumn{4}{|c|}{ HM medium } \\
\hline & $\begin{array}{c}\text { Auxiliary } \\
\text { buds }^{z} \text { (No.) }\end{array}$ & $\begin{array}{c}\text { Shoot } \\
\text { length }^{\mathrm{y}}(\mathrm{cm})\end{array}$ & $\begin{array}{l}\text { Fresh } w^{x} \\
(\mathrm{mg})\end{array}$ & $\begin{array}{l}\text { Dry } w^{w} \\
(\mathrm{mg})\end{array}$ & $\begin{array}{l}\text { Auxiliary buds }{ }^{z} \\
\text { (No.) }\end{array}$ & $\begin{array}{l}\text { Shoot length } \\
(\mathrm{cm})\end{array}$ & $\begin{array}{l}\text { Fresh } \mathrm{wt}^{\mathrm{x}} \\
(\mathrm{mg})\end{array}$ & $\begin{array}{l}\text { Dry } w^{w} \\
(\mathrm{mg})\end{array}$ \\
\hline Tonda Giffoni & $5.0 \pm 0.2$ & $2.0 \pm 0.8$ & $228.0 \pm 0.5$ & $50.0 \pm 0.7$ & $6.0 \pm 0.3$ & $1.8 \pm 0.8$ & $277.0 \pm 0.5$ & $80.3 \pm 0.7$ \\
\hline Tonda Romana & $3.0 \pm 0.3$ & $1.5 \pm 0.8$ & $190.5 \pm 0.5$ & $55.1 \pm 0.7$ & $4.5 \pm 0.3$ & $1.8 \pm 0.8$ & $195.0 \pm 0.5$ & $58.0 \pm 0.7$ \\
\hline Mortarella & $4.1 \pm 0.3$ & $2.3 \pm 0.8$ & $190.5 \pm 0.5$ & $57.1 \pm 0.7$ & $7.0 \pm 0.3$ & $2.1 \pm 0.8$ & $252.3 \pm 0.5$ & $75.7 \pm 0.7$ \\
\hline Ghirara & $5.3 \pm 0.3$ & $2.7 \pm 0.8$ & $143.0 \pm 0.5$ & $41.5 \pm 0.7$ & $4.0 \pm 0.3$ & $2.5 \pm 0.8$ & $150.0 \pm 0.5$ & $43.5 \pm 0.7$ \\
\hline Avellana Speciale & $3.7 \pm 0.3$ & $0.8 \pm 0.8$ & $175.0 \pm 0.5$ & $35.5 \pm 0.7$ & $4.2 \pm 0.3$ & $1.4 \pm 0.8$ & $173.1 \pm 0.5$ & $47.5 \pm 0.7$ \\
\hline Napuletanedda & $5.0 \pm 0.3$ & $1.5 \pm 0.8$ & $149.0 \pm 0.5$ & $30.8 \pm 0.7$ & $4.5 \pm 0.3$ & $2.4 \pm 0.8$ & $188.0 \pm 0.5$ & $52.0 \pm 0.7$ \\
\hline
\end{tabular}

${ }^{\mathrm{z}}$ Mean number of auxiliary buds/shoots.

${ }^{\mathrm{y}}$ Mean length of new shoots.

${ }^{\mathrm{x}}$ Fresh and dry weight.

wer shoots \pm SE.

The Wilks' Lambda test was significant for genotype (14.9), medium (31.3), and the interaction cultivar $\times$ medium $(4.4)$ at $P<0.001$.

All main effect and interaction for number of auxiliary buds and fresh and dry weight shoots were significant at $P=0.05$ except for shoot length.

$\mathrm{HM}=$ new medium; MS = Murashige and Skoog (1962) both supplemented with vitamins MS, gibberellic $\mathrm{A}_{3} 0.4 \mathrm{mg} \cdot \mathrm{L}^{-1}$, indole-3-butirric acid $0.05 \mathrm{mg} \cdot \mathrm{L}^{-1}$, $3 \%$ sucrose, and 6-benzylamminopurine $\left(0.5 \mathrm{mg} \cdot \mathrm{L}^{-1}\right)$. 
differentiated the highest number of auxiliary buds when the culture started from explants collected during spring. Differences among plant growth regulators in C. avellana tissues collected in different period of the year were reported by different authors (Rodriguez et al., 1991; Rodriguez and Sanchez-Tamès, 1986). Hazelnut tissues in the active growth period showed high levels of indole-3-acetic acid and total cytokinins (above all $2 \mathrm{iP}$ and zeatin), which enhance and facilitate in vitro organogenesis (Andres et al., 2002; Davies, 1995; Rey et al., 1994). Significant differences were found for the season $\times$ genotypes interaction in the auxiliary number of buds.

Proliferation phase. In vitro culture of hazel explants from somatic tissues is still limited owing to the low multiplication rate (Yu and Reed, 1993). In materials collected during spring, a different response among cultivars was observed in the media supplemented with zeatin $\left(1 \mathrm{mg} \cdot \mathrm{L}^{-1}\right)$ or BA $(1.5$ $\mathrm{mg} \cdot \mathrm{L}^{-1}$ ) (Fig. 2). The two-way analysis of variance showed a significant differences among cultivars as well as a significant interaction cultivars $\times$ media. The Student's $t$ test performed on the number of auxiliary buds developed by each cultivars on the two media showed significant differences at $P<$ 0.05 except for cv. Ghirara. On the other hand, zeatin seemed to promote the best shoot proliferation in cvs. Tonda Romana, Mortarella, and Avellana Speciale; on the contrary, BA was more suitable for bud outgrowth of the cvs. Napoletanedda and Tonda Giffoni. Both of the two cytokinins had an analogous effect on shoot development in cv. Ghirara. Probably hazelnut cultivars are characterized by the different levels of endogenous cytokinins involved in the regulation of vegetative growth. Andres et al. (2002) showed that the $2 \mathrm{iP} /$ zeatin ratio affects the morphogenetic capacity of Corylus avellana tissues, indicating this value as an indicator of the in vitro morphogenetic competence of explants. In any case, no lateral buds or adventitious shoots developed.

Rooting phase. Any root induction was obtained from shoot immersion in IBA solution. Basically the different cultivars showed a poor root system in the solid medium supplemented by IBA $\left(2 \mathrm{mg} \cdot \mathrm{L}^{-1}\right)$. Thirty percent of cv. Tonda Romana shoots developed $2.1 \pm 0.7$ roots/explants, whereas only $20 \%$ of cv. Tonda Giffoni differentiated $1.5 \pm$ 0.6 roots/explants. A lower percentage $(10 \%)$ of rooted shoots was obtained from cvs. Mortarella and Ghirara. No root formation was observed in cvs. Napoletanedda and Avellana Speciale (Table 5).

\section{Conclusions}

Micropropagation is a technique applied with success in economically important hazelnut cultivars. Local genotypes or selected hybrids can give contradictory responses to in vitro culture showing even recalcitrant behavior. As suggested by Nas and Read (2004), one factor determining the success of micropropagation is the use of an

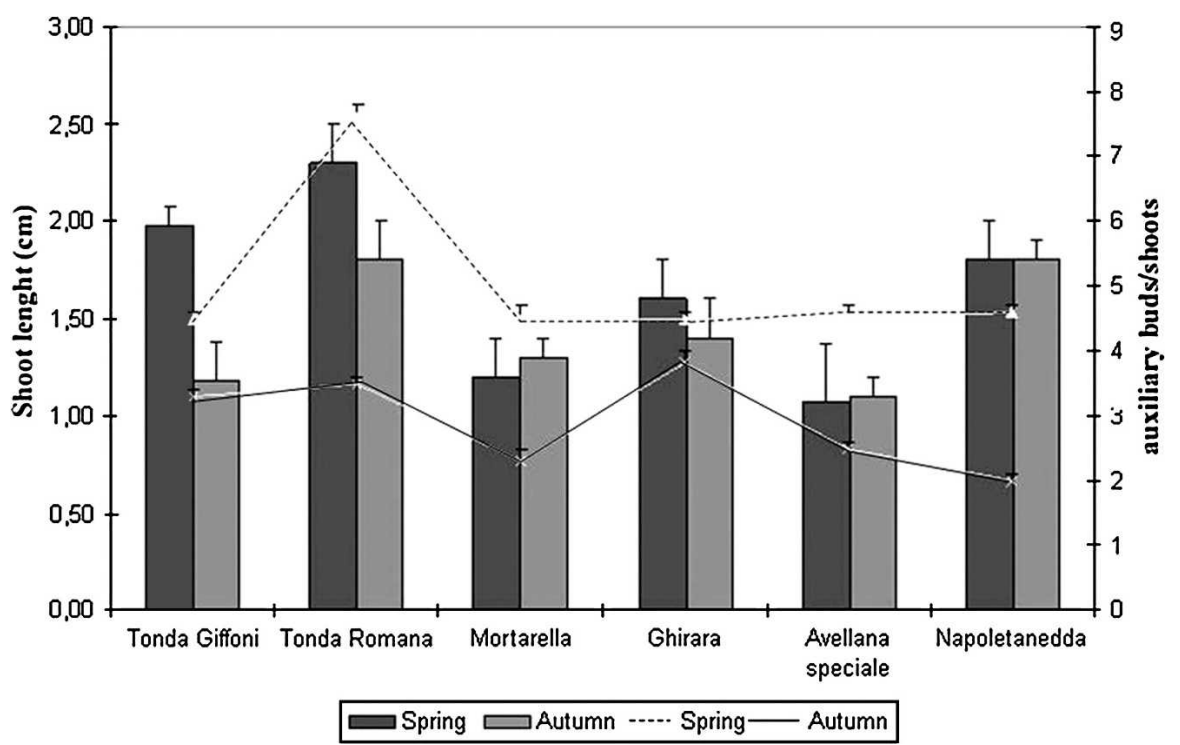

Fig. 1. Means shoot lengths (columns) and number of auxiliary bud/shoot (lines) of Italian cultivars micropropagated during spring or winter on HM induction medium for $30 \mathrm{~d}$. The multivariate analysis, Wilks' lambda test was significant for interaction cultivar $\times$ season (value $=0.37, \mathrm{~F}=2.8, P=0.004$ ). The test between subject effect showed significant value for auxiliary buds number (mean square $=$ $3.49, \mathrm{~F}=4.7, P=0.001)$. All main effects and interaction for shoot length and number of auxiliary buds were significant at $P=0.05$. Bars represent SE $(\mathrm{n}=6)$.

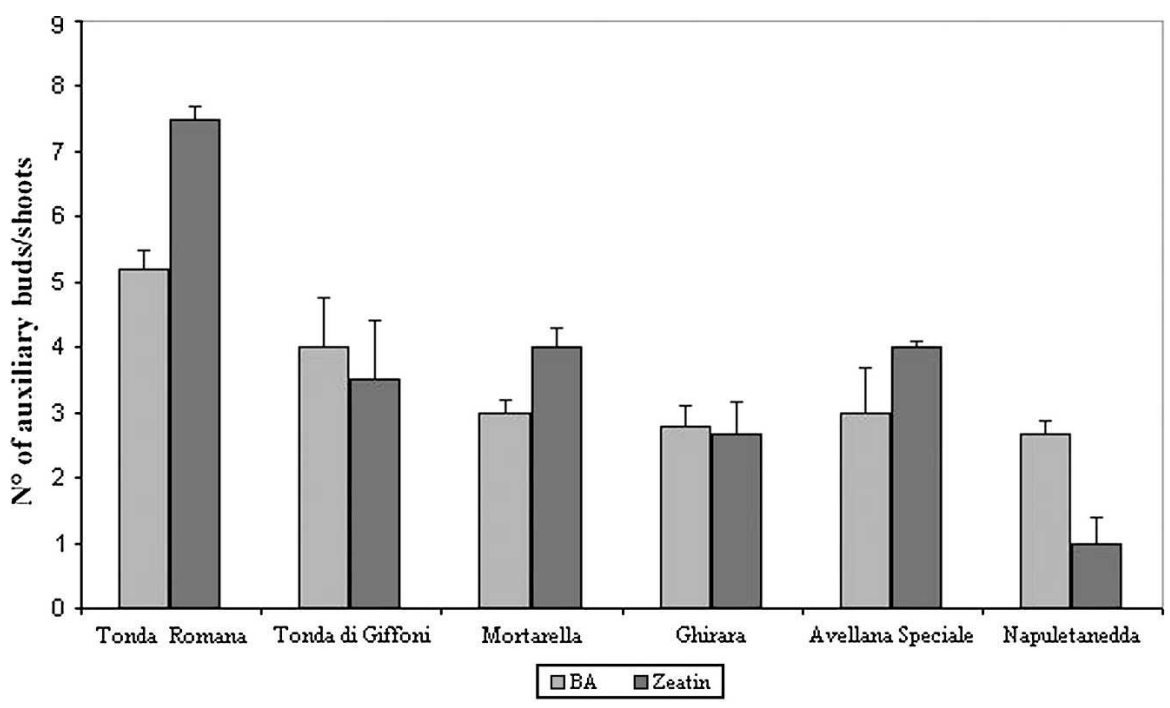

Fig. 2. Mean values of auxiliary buds/shoots of Italian cultivar (Tonda Romana, Tonda Giffoni, Mortarella, Ghirara, Avellana Speciale, Napoletanedda) spring explants inoculated for 8 weeks on medium supplemented with 6-benzylamminopurine $\left(1.5 \mathrm{mg} \cdot \mathrm{L}^{-1}\right)$ or zeatin $\left(1 \mathrm{mg} \cdot \mathrm{L}^{-1}\right)$. Significant differences were shown among varieties and for cultivars $\times$ medium at $P=0.05$. Bars represent SD $(\mathrm{n}=6)$. Student's $t$ test showed significant differences at $P<0.05$ between the number of auxiliary buds developed by each varieties on the two media except for cv. Ghirarà.

Table 5. Rooting response of in vitro shoots after 4 weeks on one-third HM medium supplemented with $2 \mathrm{mg} \cdot \mathrm{L}^{-1}$ indole-3-butirric acid.

\begin{tabular}{lcc}
\hline Cultivars & \multicolumn{1}{c}{ Rooting response } & Root/explant (no. $\pm \mathrm{SD})$ \\
\hline Tonda Romana & $30 \%$ shoots with good rooting system & $2.1 \pm 0.7$ \\
Tonda Giffoni & $20 \%$ shoots with poor roots & $1.5 \pm 0.6$ \\
Napoletanedda & - & - \\
Avellana Speciale & - & $2.2 \pm 0.5$ \\
Mortarella & $10 \%$ shoots with good roots system & $1.8 \pm 0.3$ \\
Ghirara & $10 \%$ shoots with discrete roots \\
\hline
\end{tabular}

optimized culture medium, suitable for a large number of genotypes. Starting from the same hypothesis, the medium developed in this research seems to be effective in producing qualitatively superior shoots (improvement of fresh and dry shoot weight).

Moreover this approach, applied in the hazelnut as a model plant, could represent a 
potentially feasible and rapid procedure for the development of specific culture medium composition in a large number of higher plant species.

The success of in vitro propagation also depends on the physiological stage of the primary explants. The use of nodal shoot segments collected during spring or the coldtreated single buds derived from dormant materials can guarantee plantlets more suitable for in vitro, commercial-scale large hazel propagation.

Further studies are needed to optimize the multiplication phase by stimulating multiple shoots/explants. In fact, there have been relatively few reports with consistent positive results for proliferation (Damiano et al., 2005; Yu and Reed, 1993).

On the other hand, the significant crucial stage in hazelnut micropropagation is rhizogenesis. Different endogenous (physiological stage, rejuvenation) and external (mineral and hormone concentration, physical parameters) factors can strongly affect the development of suitable root systems capable of overcoming the acclimatizing phase. Further research is necessary on these aspects to make in vitro propagation a valid and reliable alternative technique to traditional clonal propagation and a valuable way of conserving hazelnut genetic resources.

\section{Literature Cited}

Andres, H.B., R. Fernandez, R. Rodrigez, and A. Rodrigez. 2002. Phytormone contents in Corylus avellana and their relationship to age and the developmental process. Plant Cell Tissue Organ Cult. 70:173-180.

Bacchetta, L., C. Bernardini, G. Di Stefano, O. Pelliccia, G. Cavicchioni, and R. Di Bonito. 2005. Molecular characterization by RAPDs markers and micropropagation of Italian hazelnut cultivars. Acta Hort. 686:99-104.

Damiano, C., E. Catenaro, J. Giovinazzi, A. Frattarelli, and E. Caboni. 2005. Micropropagation of hazelnut (Corylus avellana). Acta Hort. 686:221-226.

Davies, P.J. (1995). The plant hormones: Their nature, occurrence and functions, p. 1-12. In: Davies, P.J. (ed.). Plant hormones. Kluvier Academic Publisher, Dordrecht, The Netherlands.

Diaz-Sala, C., M. Rey, and R. Rodriguez. 1990. In vitro establishment of a cycloclonal chain from nodal segments and apical buds of adult hazel (Corylus avellana L.). Plant Cell Tissue Organ Cult. 23:151-157.

Ding, S.-P., Y.Y. Qiang, and I.J. Dao-Fan. 1985 Effect of sugar sources on plant tissue culture. J. Amer. Soc. Hort. Sci. 110:705-709.

Marino, G., G. Bertazza, E. Magnanimi, and A. Doro Altan. 1993. Comparative effects of sorbitolo and sucrose as a main carbon source in micropropagation of apricot. Plant Cell Tissue Organ Cult. 34:235-244.

Messeguer, J. and E. Mele. 1987. In vitro propagation of adult material and seedlings of Corylus avellana L. Acta Hort. 212:499-503.

Murashige, T. and F. Skoog. 1962. A revised medium for rapid growth and bioassays with tobacco tissue cultures. Physiol. Plant. 15:473497.

Nas, M.N., N. Multu, and P.E. Read. 2004. Random amplified polimorfic DNA (RAPD) analysis of long-term cultured hybrid hazelnut. HortScience 39:1079-1082.

Nas, M.N. and P.E. Read. 2004. An hypothesis for the development of a defined tissue culture medium for higher plants and micropropagation of hazelnuts. Sci. Hort. 101:189-200.

Phillips, K.M., D.M. Ruggio, and M. AshrafKhorassam. 2005. Phytosterol composition of nuts and seeds commonly consumed in US. J. Agr. Food Chem. 53:9436-9445.

Reed, B., J. Mentzer, P. Trampraset, and X. Yu. 1998. Internal bacterial contamination of micropropagated hazelnut: Identification and antibiotic treatment. Plant Cell Tissue Organ Cult. 52:67-70.

Rey, M., C. Diaz-Sala, and R. Rodrìguez. 1994. Effect of repeated severe pruning on endogenous polyamine content in hazelnut trees. Physiol. Plant. 92:487-492.

Rodriguez, A., M.J. Canal, and R. Sanchez-Tames. 1991. Seasonal changes of plant growth regulators in Corylus. J. Plant Physiol. 138: $29-32$.

Rodrìguez, A. and R. Sanchez-Tamès. 1986. Dormancy and seasonal changes of plant growth regulators in Hazel buds. Physiol. Plant. 66:228-292.

Rodriguez, R., A. Rodriguez, A. Gonzalez, and C. Perez. (1989). Hazelnut (Corylus avellana L.). In: Bajaj, Y.P.S. (ed.). Biotechnology in agriculture and forestry. Vol. 5. Trees II. SpringerVerlag, Berlin.

Rugini, E. 1984. In vitro propagation of some olive cultivars with different root-ability and medium development using analytical data from developing shoots and embryos. Scientia Horticulture 24:123-134.

Rugini, E. and D. Verma. 1983. Micropropagation of difficult to propagate almond (P. amygdalus B amigdalus) cultivar. Plant Sci. Lett. 28: 273-281.

Scortichini, M. 2002. Bacterial canker and decline of European hazelnut. Plant Dis. 86:34-38.

Sivakumar, G. and L. Bacchetta. 2006. $\alpha$-Tocopherol from Italian hazelnut germoplasm. Chem. Nat. Compd. 42:2006.

Sivakumar, G., L. Bacchetta, R. Gatti, and G. Zappa. 2005. HPLC screening of natural vitamin $\mathrm{E}$ from Mediterranean plant biofactories a basic tool for pilot-scale bioreactors production of a-tocopherol. J. Plant Physiol. 165:12801283.

Xiaoling, Yu. and B.M. Reed. 1993. Improved shoot multiplication of mature hazelnut (Corylus avellana L.) in vitro using glucose as a carbon source. Plant Cell Rep. 12:256259 